\title{
ARGUMENTAÇÃO EM FOCO: CONCEPÇÕES, REFLEXÕES E PRÁTICA DE UMA PROFESSORA DO ANO $5^{1}$
}

\section{FOCUS ON ARGUMENTATION: CONCEPTIONS, REFLECTIONS AND PRACTICE OF A YEAR 5 TEACHER}

\author{
LEAL, Telma Ferraz \\ tfleal@terra.com.br \\ Universidade Federal de Pernambuco \\ BRANDÃO, Ana Carolina Perrusi \\ carol.perrusi@ufpe.br \\ Universidade Federal de Pernambuco \\ GUERRA, Severina Erika Morais Silva \\ erikaguerra2002br@yahoo.com.br \\ Prefeitura Municipal de Recife \\ CARVALHO, Edla Ferraz Correia \\ edlaferraz@yahoo.com.br \\ Escola Conviver
}

\begin{abstract}
RESUMO Por meio de um estudo de caso, buscou-se refletir, nesta pesquisa, sobre as concepções de uma professora sobre o ensino da argumentação. A docente foi observada durante dois meses, perfazendo um total de quinze aulas gravadas, em turnos de quatro horas. Após essa etapa, a professora foi entrevistada e solicitada a analisar, em voz alta, a transcrição de uma aula na qual outra professora propôs atividades dirigidas para o desenvolvimento de habilidades argumentativas. As análises das aulas e da entrevista revelaram que a docente tinha apenas uma forma de ensinar argumentação: ler um texto, fazer perguntas e discutir. Nós concluímos que tal concepção pode resultar de uma reflexão pouco desenvolvida sobre os gêneros discursivos e práticas de linguagem na formação da docente.
\end{abstract}

Palavras-chave: Argumentação. Leitura. Prática docente. Produção de textos.

ABSTRACT In a case of study, we have aimed to analyze a teacher's conceptions on argumentation teaching. The teacher was observed for two months, mounting to a total of 15 classes recorded, in four-hour turns. After this phase, the teacher was interviewed and requested to analyze, loudly, the transcription of activities conducted by another teacher which aimed to develop argumentative abilities. The analyses of the classes and the interview revealed that there was only one way to teach argumentation: reading a text, asking questions and discussing. We concluded that that such conception is consequence of little reflection on discursive genres and language practices in the teacher's training.

Key-words: Argumentation. Teacher's practice. Reading. Text production.

\footnotetext{
${ }^{1}$ Apoio do CNPq e FACEPE
} 


\section{INTRODUÇÃO}

Neste artigo, relatamos uma pesquisa em que, por meio de um estudo de caso, refletimos sobre as concepções de uma professora sobre o ensino da argumentação. A escolha dessa temática advém da concepção de que a escola tem, dentre outros objetivos, o papel de estimular o desenvolvimento da capacidade de análise crítica de textos orais e escritos quanto à sua pertinência e consistência argumentativa, assim como de produção de textos em diferentes contextos para defender pontos de vista sobre temáticas sociais relevantes, ampliando, portanto, as condições de participação em diferentes contextos sociais de interação.

Citelli (2000, p.7), ao tratar sobre a emergência das relações entre argumentação e ensino, afirma que a partir da democracia grega a argumentação passou a ganhar papel de destaque, pois, "tendo de expor publicamente suas ideias, ao homem grego cabia manejar com habilidade as formas de argumentação".

Na sociedade moderna, o apelo à participação nas instâncias democráticas e a defesa de que cabe aos diferentes grupos sociais defender direitos e valores justificam a necessidade de tematizar tal objeto de ensino. Assim, o trabalho pedagógico relativo à argumentação tem ocupado, embora ainda de modo incipiente, espaço entre pesquisadores de diferentes países. Considerando, portanto, o tema da presente investigação, iniciaremos situando o leitor quanto à concepção de ensino de argumentação adotada no estudo.

\section{ARGUMENTAÇÃO E ENSINO DA LÍNGUA PORTUGUESA}

As referências aos estudos sobre argumentação são, sem dúvida, bastante remotas. Correntes teóricas de cunho filosófico têm servido de base para diferentes autores. Alusões à Retórica, à Lógica e à Dialética são frequentes. Autores como Perelman e Olbrechts-Tyteca (1996), por exemplo, fazem referência aos estudos sobre Retórica desde a antiguidade e Citelli (2000) refere-se à Grécia Clássica para contextualizar o ensino da retórica. Assim, não é nova a discussão sobre o funcionamento da argumentação e nem sobre o seu ensino.

Apesar disso, observações decorrentes deste e de estudos anteriores, conforme será descrito adiante, indicam um baixo investimento no desenvolvimento de habilidades argumentativas na escola e nos livros didáticos de língua portuguesa 
para as séries iniciais.

Tal constatação foi feita, por exemplo, em uma pesquisa em que, buscando entender as práticas de ensino de textos da ordem do argumentar, realizamos quinze observações em salas de aula de cinco professoras do ano 5 do Ensino Fundamental de escolas públicas. Naquele estudo, pretendíamos apreender os momentos das aulas em que havia possibilidades para o desenvolvimento de habilidades argumentativas. Dentre outros resultados, pudemos verificar que, de fato, a incidência de práticas dirigidas ao ensino da argumentação foi baixa, o que nos fez perguntar por que a freqüência desse tipo de atividade era tão reduzida.

Naquela mesma investigação, foram conduzidas entrevistas de aprofundamento com as professoras observadas. A análise das entrevistas mostrou que as docentes do ano 5 consideravam importante e possível ensinar as crianças a argumentar nessa etapa de escolarização. No entanto, mostravam-se angustiadas por terem dificuldades para conduzir tal ensino.

Assim como as docentes entrevistadas no estudo citado, defendemos, adotando uma perspectiva sociointeracionista, que a argumentação pode e deve se desenvolver em diferentes situações na sala de aula em que os alunos sejam estimulados a expor e defender seus pontos de vista, seja num debate regrado sobre temas polêmicos, seja em situações em que precisam tomar uma decisão coletiva ou, simplesmente, quando desejam convencer pessoas a serem favoráveis a uma posição assumida ou a uma determinada ideia proposta em uma discussão informal. Assim, postulamos que o trabalho com argumentação na escola pode ser favorecido por meio de intervenções centradas em interações diversificadas, em que diferentes gêneros textuais circulem.

Neste contexto, adotamos a perspectiva bakhtiniana de gênero discursivo, segundo a qual,

Uma dada função (científica, técnica, ideológica, oficial, cotidiana) e dadas condições, específicas para cada uma das esferas da comunicação verbal, geram um dado gênero, ou seja, um dado tipo de enunciado, relativamente estável do ponto de vista temático, composicional e estilístico. (BAKHTIN, 2000, p. 284)

Tal opção fundamenta-se no pressuposto de que, 
Ignorar a natureza do enunciado e as particularidades de gênero que assinalam a variedade do discurso em qualquer área do estudo lingüístico leva ao formalismo e à abstração, desvirtua a historicidade do estudo, enfraquece o vínculo existente entre a língua e a vida. (BAKHTIN, 2000, p. 282)

Neste texto, não pretendemos, portanto, introduzir um tema novo na esfera acadêmica. Porém, como já afirmamos, sob nosso ponto de vista, faz-se necessária uma maior compreensão acerca dos motivos para a baixa incidência de trabalhos com argumentação na escola e das supostas dificuldades apontadas por professores. Buscamos, assim, com este estudo, abordar tal tema, objetivando evidenciar a importância de contemplarmos, nos processos de formação inicial e continuada, o ensino da argumentação na perspectiva do trabalho com gêneros discursivos. As análises dos dados expostas no decorrer desse artigo evidenciarão que a falta de conhecimentos mais sistemáticos sobre os gêneros da ordem do argumentar e sobre a didatização desses gêneros pode ter sido um dos fatores que dificultou o planejamento e o desenvolvimento de ações didáticas mais consistentes para o ensino de habilidades argumentativas pela docente investigada.

Para iniciar esta reflexão, citaremos, em seguida, alguns estudos que tratam da questão do ensino da argumentação nos anos iniciais do Ensino Fundamental.

Uma investigação relativa a tal tema foi realizada por Leal e Morais (2006), que analisaram aulas de doze professoras de segunda a quarta séries de escolas públicas da Região Metropolitana do Recife. Os autores constataram uma baixa frequência de situações de escrita de textos em que era necessário defender um ponto de vista. Tal resultado confirma dados de pesquisa de outros autores que já tinham acusado essa carência de atividades de leitura e de produção de textos em que se busca argumentar na escola (BEZERRA, 2001; BRASSART, 1990; DOLZ, 1996; LOPES, 1998).

Leal e Morais (2006) identificaram muitas diferenças entre as turmas investigadas. Eles perceberam que algumas docentes solicitavam que seus alunos produzissem textos em situações em que o gênero, a finalidade e o destinatário da escrita, eram claramente delimitados. Segundo os autores, os grupos de crianças regidos por essas professoras produziam textos com maior consistência argumentativa que os demais, regidos por outras professoras. Com base nesse resultado, foi levantada a hipótese de que as crianças que eram mais acostumadas 
a escrever atendendo a diferentes finalidades escreviam textos mais consistentes por estarem mais atentas aos seus interlocutores. Outra hipótese, não excludente em relação à primeira, é que esse resultado decorra do fato de que, ao escrever para diferentes finalidades na escola, 0 aluno perceba mais claramente a variabilidade de possibilidades para interagir por meio do texto escrito, passando, dessa forma, a diversificar mais as estratégias discursivas adotadas em seus textos.

Ainda em relação aos efeitos da prática pedagógica, foi identificada uma influência das práticas de reflexão em sala de aula. Os alunos das professoras que eram estimulados a refletir sobre dimensões textuais em variadas situações de escrita tendiam a utilizar estratégias argumentativas mais elaboradas, que demandavam dos leitores a construção de inferências, em oposição a textos em que as idéias eram apresentadas de modo mais explícito e direto. Além disso, esses alunos costumavam diversificar mais os modos de introduzir os pontos de vista do que aqueles das salas em que não se promovia esse tipo de reflexão. Desse modo, os autores evidenciaram a relevância de ações didáticas e processos de mediação docente no desenvolvimento de capacidades de lidar com textos da ordem do argumentar das crianças.

Pesquisadores como Dolz (1996), Lopes (1998), Rosenblat (2000) e Almeida (2003), corroboram tal pressuposto, pois, cientes da precariedade do trabalho com argumentação na escola, planejaram e desenvolveram intervenções voltadas à produção de textos da ordem do argumentar. Os autores relataram que em poucas sessões os alunos já eram capazes de produzir tais textos de modo mais consistente.No entanto, como foi salientado anteriormente, professores têm relatado dificuldades para organizar a prática pedagógica com foco na argumentação. Por tal motivo, neste artigo apresentaremos reflexões oriundas de uma pesquisa em que buscamos compreender quais eram as concepções das professoras acerca do ensino da argumentação e como tais concepções poderiam estar subjacentes às estratégias didáticas por elas elaboradas.

\section{METODOLOGIA DO ESTUDO}

Este artigo, como explicitado no resumo, reflete sobre as concepções de uma professora sobre o ensino da argumentação e os modos como tais concepções 
interferem nas suas opções didáticas. A pesquisa de origem, no entanto, contempla uma quantidade maior de sujeitos participantes e mais etapas de coleta de dados.

A fase 1 da pesquisa constou de observações de quinze aulas realizadas com apoio de gravador e filmadora de cinco professoras do ano 5 do Ensino Fundamental de escolas públicas. Como já foi anunciado, são discutidos neste artigo apenas os dados relativos à professora selecionada para este estudo de caso, que passamos a chamar de "Maria". Tal professora foi escolhida porque entre as quinze aulas observadas em sua sala, três apresentaram tentativas de desenvolver as habilidades argumentativas de seu grupo de alunos. Tal número foi considerado significativo, tendo em vista que do total de setenta e cinco aulas registradas (quinze aulas de cada uma das cinco professoras), em apenas seis aulas identificamos tentativas dessa natureza, sendo três aulas da professora Maria.

$\mathrm{Na}$ fase 2 da pesquisa foram feitas entrevistas com as docentes observadas, com questões relativas ao ensino da argumentação, buscando apreender se elas valorizavam esse ensino, o que elas concebiam como ensinar argumentação e quais dificuldades elas apontavam para tal trabalho.

$\mathrm{Na}$ fase 3, solicitamos às docentes que lessem e analisassem um relatório de aula, descrito no parágrafo seguinte, que foi selecionado dentre os setenta e cinco relatórios coletados na pesquisa com as cinco docentes. Neste artigo, discutiremos apenas os dados relativos ao modo como Maria avaliou a aula descrita no relatório.

O procedimento dessa etapa de coleta de dados foi o seguinte: a professora lia o relatório e analisava a aula descrita no relatório com base nas seguintes questões:O que você achou da atividade?; Quais foram os aspectos positivos e os negativos?; O que os alunos podem ter aprendido nesta atividade?; Você acha que a professora contribuiu para o desenvolvimento das capacidades argumentativas das crianças? Como?; O que ela fez que pode ter ajudado? Em que parte da aula?; $\mathrm{O}$ que poderia ter sido feito para que a atividade fosse melhor?; $\mathrm{E}$ para ajudar a desenvolver capacidades argumentativas, o que poderia ter sido melhorado?

No relatório citado acima foram relatadas as atividades realizadas por uma professora do ano 5 do Ensino Fundamental participante da fase 1 desta pesquisa, conforme descrição anterior.

A aula descrita no relatório começou com a docente falando que os alunos iriam assistir a um filme (Mulan) e depois seria feito "um debate". Após o filme, ela 
iniciou uma conversa, levantando as seguintes questões: "O que vocês acharam desse filme?"; "Quero saber o que vocês acharam da mensagem que o filme passa."; "Fala de uma guerra de um país. Que país era esse?"; "Mas tem uma pessoa, um personagem principal. Qual é o nome dela?". Na dinâmica da aula, a professora fazia as perguntas e as crianças respondiam com frases curtas. Ela complementava as respostas e fazia comentários, não concedendo espaço para as intervenções das crianças. Como vemos no fragmento abaixo, a própria docente fez um resumo do filme e emitiu sua opinião:

P A mulher é uma heroína.

A São não.

$\mathrm{P} \quad$ Somos sim! Porque se sua mãe trabalha fora, trabalha que só naquele emprego, rala muito, né?! E quando chega em casa está tudo pronto?!

A Não.

A Ela tem que arrumar, fazer comida...

P Muito bem, José, você está valorizando mesmo sua mãe e as mulheres! A mulher quando chega em casa tem que cuidar da alimentação, dos filhos, do marido... Por isso, quando a mãe de vocês disser: fulana, me ajuda aqui, varre essa casa!

A Varro nada!

P Não pode! Não só as meninas, mas todos os meninos também. Não custa nada varrer a casa, lavar os pratos de vez em quando, lavar o banheiro, lavar as cuecas e as calcinhas. Para começar a ter o sentido de higiene pessoal. Tudo a gente tem que lavar.

Neste diálogo, é possível verificar que a professora possibilitou que diferentes pontos de vista entrassem em confronto, mas não organizou a discussão, fazendo com que a situação se assemelhasse mais a uma exposição escolar, em que a professora explica determinado conteúdo, com objetivo de que os alunos se apropriem das informações. No momento em que parece surgir uma possível polêmica, ela interdita a discussão, prevalecendo a sua fala e a sua opinião.

Em outras palavras, apenas o conteúdo do filme ou de temas que ele pode suscitar é que parece ser objeto de ensino e não o gênero debate, já que não se observam intervenções planejadas para o desenvolvimento de habilidades mobilizadas por meio desse gênero oral. Assim, não se reflete sobre o que é um debate, como ele se organiza, em que situações ele pode aparecer, como são tais situações ou como se comportam as pessoas em situações de debate. Também não se evidencia uma proposta de levar os estudantes a fazer intervenções mais 
Blumenau, v. 11, n.1, p.138-158, jan./abr. 2016

DOI: http://dx.doi.org/10.7867/1809-0354.2016v11n1p138-158

consistentes, a explicitar e defender melhor seus pontos de vista, a contraargumentar, a monitorar o tempo de fala, dentre outras habilidades que poderiam ser estimuladas em situações de debate. Por fim, não houve, também, estímulo a reflexões sobre as estratégias discursivas dos personagens do filme.

Com a proposta de leitura e análise desse relatório, buscamos verificar se Maria era sensível a tais questões, mesmo que de modo intuitivo.

\section{RESULTADOS}

\subsection{A PROFESSORA MARIA: ANÁLISE DE AULAS E ENTREVISTA}

Maria, no momento das observações de aula, atuava no turno da tarde, com uma turma de vinte alunos. Ela utilizou, nas aulas observadas, variados gêneros discursivos: letra de música, carta pessoal, um extrato da Constituição Brasileira, relato histórico, mapa, texto didático. Tal diversidade evidenciava uma preocupação da docente em propiciar variadas situações de leitura e escrita, aproximando os alunos das práticas sociais em que diferentes gêneros circulam.

Apesar da ausência de textos da ordem do argumentar entre os selecionados pela professora,alguns textos utilizados por ela possibilitavam atividades voltadas para 0 desenvolvimento de capacidades argumentativas, pois favoreciam que diferentes pontos de vista emergissem no discurso produzido pelos participantes da situação. Desse modo, as situações eram propícias à condução de reflexões sobre esses diferentes pontos de vista. Como é apontado por Thives (2008, p.2), para Bakhtin, o dialogismo e a heteroglossia ${ }^{2}$ podem ser analisados no discurso, quando diferentes olhares no mundo são integrados a ele através de variados discursos.

Os textos selecionados pela docente mobilizavam temas favoráveis para um debate e, consequentemente, para o confronto de ideias e estímulo à argumentação, assim como para a reflexão sobre como diferentes olhares no mundo são integrados no discurso.

Nas quinze aulas observadas, foram registrados seis momentos em que tais

\footnotetext{
${ }^{2}$ No dialogismo, a heteroglossia se caracteriza pela diversidade de linguagens e de vozes que entram em um campo de tensões e interconexões em pé de igualdade. (p. 2)
} 
Blumenau, v. 11, n.1, p.138-158, jan./abr. 2016

DOI: http://dx.dol.org/10.7867/1809-0354.2016v11n1p138-158

tipos de reflexão eram mais fortemente favorecidas. Em pelo menos três deles,essa possibilidade foi aproveitada e serão a seguir descritas.

Em uma das aulas,após a leitura de um trecho da constituição, os alunos discutiram sobre o referendo acerca do desarmamento. Em outra aula observada, após lerem um relato histórico sobre a sociedade pernambucana, debateram sobre a vida em sociedade, a importância das normas e leis e sobre o trabalho escravo, temas tratados no texto. Por fim, na terceira ocasião, após uma leitura de mapas, discutiram sobre a preferência por mapas novos ou antigos. Vê-se, pois, que as três situações contemplavam temas passíveis de discussão, ou seja, temas sobre os quais diferentes pontos de vista eram facilmente detectáveis. No caso da discussão sobre o referendo, havia argumentos contra e a favor do desarmamento; na aula em que foi realizada a leitura do relato histórico, a pertinência ou não de haver leis específicas para defender os direitos dos negros mobilizava diferentes pontos de vista; na aula em que o tema era mapas, havia argumentos para a defesa de que os mapas novos são melhores e pontos de vista em que se defendia que os de antigamente eram melhores. A possibilidade de existência de diferentes pontos de vista, portanto, tornava os temas passíveis de debates.

As três situações descritas acima se estruturaram de modo similar: leitura de um texto que mobiliza um tema passível de debate, seguido de discussão sobre o tema mobilizado.

Nessas situações, a escrita e a oralidade foram articuladas nas aulas. Como é afirmado por Machado (2007, p.161), "os gêneros discursivos sinalizam as possibilidades combinatórias entre as formas de comunicação oral imediata e as formas escritas".De fato, as relações entre oralidade e escrita são múltiplas e é importante que na escola possam ser vivenciadas. O uso do texto escrito para alimentar o discurso oral é uma dessas formas de articulação. No entanto, há outras possibilidades de relações, na escola e fora dela, como o uso da escrita como apoio na própria situação de produção oral, como o uso de anotações e slides em uma exposição oral; o uso da oralidade para coleta de informações para a produção oral, como o uso de entrevistas para a produção de uma reportagem; uso da escrita para registrar informações expostas em produção oral; dentre outras, que não foram estimuladas por Maria.

Em relação ao eixo de produção de textos, diferentemente do que aconteceu 
Blumenau, v. 11, n.1, p.138-158, jan./abr. 2016

DOI: http://dx.doli.org/10.7867/1809-0354.2016v11n1p138-158

com o eixo de leitura, não foram registradas propostas de escrita em que os alunos tivessem que defender pontos de vista.

Apesar da pouca diversificação nos modos de relação entre oralidade e escrita, as observações de aula evidenciaram que Maria era guiada por uma perspectiva em que o texto assumia um lugar de destaque no ensino, e não a teorização gramatical como, frequentemente, ocorre em outras práticas.

As observações das aulas, como foi evidenciado nos parágrafos anteriores, evidenciaram que Maria tentava abarcar o ensino da argumentação, porém, os procedimentos adotados eram restritos a um único modelo: leitura e discussão do texto, cuja temática mobilizava um tema polêmico.

Não foi registrado planejamento de situações em que gêneros da ordem do argumentar pudessem ser usados, nem proposta de produção de textos dessa ordem ou atividades de leitura de textos propriamente argumentativos, tais como uma carta de reclamação ou um cartaz educativo. Consequentemente, também não havia discussão sobre as dimensões argumentativas dos textos.

Em síntese, o texto apenas servia de motivação para a discussão de um tema. Os pontos de vista dos autores não eram colocados em confronto com os pontos de vista dos alunos e muito menos a consistência argumentativa do discurso promovido em textos da ordem do argumentar era objeto de atenção.

Nas análises das aulas, foi possível reconhecer princípios pedagógicos alinhados com abordagens enunciativas presentes no discurso atual sobre o ensino de língua materna, como o princípio de trabalhar com textos autênticos, integrais, diversificar os gêneros utilizados em sala de aula, promover reflexões coletivas sobre os textos, enfocar os diferentes sentidos textuais. No entanto, a docente não conseguia explorar as diferentes vozes presentes nos textos discutidos ou nos textos orais produzidos pelos próprios estudantes.

É possível que a própria carência de discussões sobre essa temática nos programas de formação inicial ou continuada, ou mesmo nos livros do saber, como os livros didáticos, seja uma das razões para as dificuldades encontradas pela professora, que, tal como os dados indicam, tentava manter uma postura mais progressista em seu modo de lidar com o ensino da leitura, escrita e oralidade, mas não mediava situações de reflexões mais aprofundadas sobre as práticas de linguagem. No tocante ao ensino da argumentação, as dificuldades aumentavam. 
Blumenau, v. 11, n.1, p.138-158, jan./abr. 2016

DOI: http://dx.doi.org/10.7867/1809-0354.2016v11n1p138-158

$\mathrm{Na}$ entrevista realizada, a professora conceituou argumentação como "dar opinião". Essa, sem dúvidas, é uma dimensão importante do processo de argumentação. No entanto, os exemplos de atividades dados por ela evidenciaram que ela fazia referência às situações de dar opinião em situação de discussão oral. Não houve em nenhum momento da entrevista referência a outros tipos de situações em que textos da ordem do argumentar circulam.Leal et al (2012), ao abordarem o conceito de argumentação, discutem, ao menos, três tipos de situações em que os textos da ordem do argumentar estão presentes: (1) "Situações em que pontos de vista acerca de temas polêmicos são colocados em confronto", mobilizando gêneros como debates de fundo controverso, discursos políticos, artigo de opinião de jornal, reportagens, carta de leitores, dentre outros; (2) "Situações em que se busca orientar o comportamento ou convencer de que determinada atitude deve ser valorizada", com a presença de gêneros como cartazes de campanha educativa, carta de reivindicação, carta de reclamação, dentre outros; (3) "Situações em que coletivamente se tenta construir uma ideia, resolver um problema ou deliberar sobre algo", em que são comuns gêneros como debate deliberativo, debate para resolução de problemas, conversas para se resolver um problema,

A professora fazia referência sempre a situações de conversa informal em sala de aula, de modo que ficou evidente a pouca incursão em outros tipos de situações em que emergem atividades argumentativas. No início da entrevista, inclusive, ela afirmou que nunca havia trabalhado com texto argumentativo. Assim, foi possível verificar que ela tinha uma concepção de argumentação muito restrita. $A$ partir do momento em que citamos alguns gêneros, ela relatou que já tinha desenvolvido atividades com eles. A resposta dada fornece indícios de que ela não reconhecia tais gêneros como argumentativos. Ao ser informada que o anúncio classificado e o anúncio publicitário, por exemplo, eram argumentativos, ela então relatou que já tinha realizado trabalhos com tais espécies de textos. Disse que explorava esses textos fazendo debates. A docente afirmou também que tinha trabalhado com artigo de opinião, mas quando solicitada a relatar como transcorreram as aulas foi possível perceber que o gênero midiático artigo de opinião não tinha sido, de fato, utilizado por ela. Na verdade, ela estava se referindo ao gênero escolar "texto de opinião", pois os alunos escreveram redação sobre temas propostos por ela. 
A professora declarou na entrevista que considerava trabalhar com a argumentação oral uma tarefa fácil, pois os alunos podiam dar sua opinião. Porém, ao ser questionada sobre a argumentação escrita, disse que julgava o trabalho difícil, tendo em vista a falta de domínio dessa ferramenta por parte de seus alunos, e não por questões ligadas às suas capacidades de argumentar.

Tal resposta oferece pistas de que, de fato, ela considerava que os gêneros orais da ordem do argumentar se restringiam à discussão em situações mais informais. Para ela, se os alunos sabiam dar opinião, eles sabiam argumentar. Não considerava a diversidade de gêneros orais dessa ordem e nem os gêneros escritos.

Tal resposta também ajuda a entender porque ela conduziu em três aulas atividades de discussão a partir de temáticas mobilizadas em textos lidos, contemplando o ensino de habilidades argumentativas orais, e não realizou qualquer atividade de produção escrita de textos argumentativos.

Nas atividades de leitura observadas nas aulas, embora as questões levantadas para a discussão fossem diversificadas, não enfocavam reflexões sobre os recursos linguísticos e estratégias argumentativas dos autores. Tal tipo de condução reflete uma ausência de abordagem da materialidade do texto decorrente, possivelmente, da falta de reflexão mais sistemática sobre os gêneros, sobretudo em relação à dimensão linguística e ao estilo do gênero.

Provavelmente, a falta de reflexão consciente de modo mais sistemático sobre as práticas de linguagem e sobre as características dos gêneros argumentativos leve, então, a docente a realizar muitas vezes intervenções didáticas pouco diversificadas de leitura e escrita.

Dolz e Schneuwly (2004) alertam, em relação ao ensino focado no trabalho com gêneros, para a importância de o docente construir modelos didáticos dos gêneros com os quais vai trabalhar. Tais modelos seriam compostos por um conjunto de características relativas aos gêneros e às práticas de linguagem nas quais os gêneros circulam considerados relevantes no currículo dos estudantes.

Machado e Cristóvão (2009), corroborando com tal posição, afirmam que "a construção desse modelo de gênero permitiria a visualização das dimensões constitutivas do gênero e seleção das que podem ser ensinadas e das que são necessárias para um determinado nível de ensino. (p. 135) 
Para as autoras citadas,

A construção desses modelos não precisa ser teoricamente perfeita e 'pura', abrindo-se a possibilidade da utilização de referências teóricas diversas, de diferentes estudos sobre o gênero a ser ensinado, além de referências obtidas por meio da observação e da análise de práticas sociais que envolvem o gênero, junto a especialistas na sua produção. (MACHADO; CRISTÓVÃO, 2009, p. 136)

As observações realizadas evidenciaram, como já foi dito, que não havia, na realidade, reflexão pela professora acerca de quais aspectos relativos ao gênero enfocar, ou mesmo em relação a quais habilidades argumentativas estimular.

Apesar da precariedade do trabalho com a argumentação verificada nas aulas observadas e na que foi relatada na entrevista, a professora enfatizou a importância do ensino da argumentação. Na entrevista também ficou claro que para ela não haveria uma etapa específica de escolarização supostamente mais adequada para esse ensino. Ao contrário, afirmou que desde o início seria possível e desejável realizar tal tipo de trabalho. Suas tentativas nas três aulas mencionadas acima comprovam esse desejo.

Veremos, então, como ela avaliou um relato de aula de outra professora observada no âmbito desta pesquisa. Tal análise nos deu novas evidências das concepções de Maria sobre o ensino da argumentação.

\subsection{Avaliação do relatório de aula por Maria}

Como foi informado anteriormente, a terceira etapa da pesquisa foi disponibilizar um relatório de aula e solicitar que Maria avaliasse os procedimentos didáticos da professora.

Ao ser questionada sobre os aspectos positivos da aula, Maria ressaltou o estabelecimento de uma finalidade didática para a atividade com o filme, evidenciando uma preocupação com um planejamento fundamentado em objetivos claros. Também ressaltou possibilidade de criticar, avaliar e argumentar com base no filme.Vejamos o que ela diz após a leitura do relatório de aula:

"Eu achei muito interessante, né? Você assistir um filme com uma finalidade, porque geralmente não é isso que acontece, não. Geralmente os meninos 
ficam calados, não tem o que fazer naquele dia, aí bota um filme.E aí, não. Achei bem interessante! Por que também a gente não tem o hábito de assistir um filme fazendo uma crítica, é como nas novelas, você assiste, aquilo vai passando na sua cabeça. A gente não tem o hábito de fazer uma crítica, né? Não é muito comum."

Maria também reconheceu o estilo pouco participativo da aula, destacando que a professora poderia ter favorecido mais a fala das crianças. Nos trechos a seguir, podemos perceber tal tipo de julgamento:

"(...)No momento em que ela fazia perguntas... Ela podia ter explorado mais, ela podia até ter... hum... dar opinião e ela dizer que não, pra ver até onde ia o argumento dele, acho que ela podia ter explorado mais nesse sentido.(...) Acho que você, mesmo que não seja a opinião da gente, tem que instigar até que ele (o aluno) fale mesmo."

Vemos no extrato acima que há, por parte de Maria, uma sensibilidade para a necessidade de estimular o aluno a emitir opiniões e a desenvolvê-las. De fato, retomando as aulas observadas na sala de Maria, pudemos verificar que ela se esforçava para abrir tal espaço e conseguiu fazer isso em três aulas. No entanto, em alguns momentos, a professora perdia oportunidades de estimular as crianças a contra-argumentar as ideias expostas por seus colegas e a desenvolverem mais seus argumentos. Assim, colocamos em destaque que a capacidade de explicitação de saberes docentes nem sempre é suficiente para pôr esse saber em ação.

Notamos ainda que ao analisar a aula, Maria não criticou a falta de reflexão sobre o gênero debate e nem o fato de não ter havido planejamento para o debate. De fato, o ensino do gênero não foi percebido como relevante. Como foi dito anteriormente, Maria não parecia ter construído um modelo didático do gênero trabalhado por ela nas aulas analisadas (discussão), que favorecesse suas intervenções no sentido de estimular mais as aprendizagens das crianças para lidar com o gênero. Do mesmo modo, não identificou que a professora da aula analisada também não parecia ter um modelo didático do gênero debate para subsidiar suas ações. As evidências apontaram que a docente tinha uma concepção de que o ensino da argumentação estaria garantido com a criação de espaços de discussão sobre os temas dos textos lidos, não sendo necessário realizar reflexões sobre os gêneros produzidos. 
A esse respeito, Dolz e Schneuwly (2004) contrapõem duas posições acerca dos procedimentos de ensino dos gêneros. De um lado, citam a abordagem do interacionismo intersubjetivo, que defende a imersão em situações de leitura e escrita, como forma de levar os estudantes a aprender a lidar com os diferentes gêneros discursivos. A outra perspectiva (interacionismo instrumental), porém, considera que os estudantes precisam ter acesso a situações sistemáticas de reflexão sobre as práticas de linguagem e os gêneros, incluindo-se as reflexões sobre os aspectos composicionais e estilísticos desses instrumentos culturais. Enfatizamos, em relação a esse segundo posicionamento, que é possível agregar a tal perspectiva a idéia de que a reflexão sobre o gênero precisa ser feita de modo articulado às experiências vivenciadas de interação por meio dos gêneros escolhidos. Isto é, não é suficiente refletir sobre os gêneros e as práticas de linguagem, é preciso também promover situações de produção / compreensão de textos de modo integrado à reflexão sobre os aspectos sociointerativos, composicionais e estilísticos do gênero.

$\mathrm{Na}$ situação avaliada pela docente, a professora poderia ter instituído, no início da aula, algumas orientações para a condução do debate, explicitando a necessidade da escuta atenta, do respeito à fala dos colegas, da necessidade de justificar suas opiniões, de identificar as opiniões diferentes, contra-argumentar ou mudar de opinião a partir dos argumentos contrários consistentes. Desse modo, o próprio gênero debate seria também objeto de ensino na aula.Como já discutimos anteriormente, estudos como o de Leal e Morais (2006) mostram o efeito de uma prática pedagógica reflexiva sobre o desempenho em escrita de estudantes. As reflexões, no estudo exposto, não eram restritas ao tema em si, mas às práticas de linguagem em que os textos circulam e sobre os gêneros discursivos em foco. Tais reflexões não foram feitas por Maria.

Ao ser questionada sobre o que os alunos podem ter aprendido na aula, ela afirma que:

"Acho que justamente aprender a criticar, a criticar no bom sentido. A criticar um filme e uma coisa que ele vê. No momento que ele critica, ele pode escolher se aquilo vai interessar a ele ou não, se é bom ou não e de fazer uma reflexão, expor as idéias dele. E com a conversa da professora que foi puxando outra coisa e trazendo conhecimentos para eles." 
Blumenau, v. 11, n.1, p.138-158, jan./abr. 2016

DOI: http://dx.doi.org/10.7867/1809-0354.2016v11n1p138-158

Como se vê no trecho da entrevista, Maria valorizava o trabalho voltado para o desenvolvimento de habilidades argumentativas. No entanto, não conseguia formular uma análise mais consistente em relação às estratégias didáticas escolhidas, ou dar sugestões para novas atividades voltadas para tal dimensão do ensino. Quando perguntada a esse respeito, Maria disse apenas que a professora deveria instigar mais os alunos a falar.

Nota-se, portanto, uma baixa capacidade de análise da situação didática colocada, assim como de perceber outras possibilidades de ensino. Assim, tanto na entrevista como na atividade de análise de uma aula fica evidente a existência de praticamente um único modo de ensinar a argumentar, que pode ser representado pelo seguinte esquema:

Ler um texto e formular perguntas aos alunos => discutir em grupo.

\section{CONCLUSÕES}

Como anunciamos anteriormente, este trabalho foi motivado pela análise de resultados de estudos de diferentes autores que indicaram uma baixa incidência de atividades didáticas destinadas ao ensino de capacidades argumentativas (LEAL, BRANDÃO E TORRES, 2009; LEAL et al, NO PRELO; LEAL E MORAIS, 2006; BEZERRA, 2001; BRASSART, 1990; DOLZ, 1996; LOPES, 1998).Desenvolver este estudo de caso foi um desafio aceito como uma tentativa de melhor entender quais poderiam ser as dificuldades enfrentadas por professoras dos anos inicias para desenvolver tais capacidades.Para isso, escolhemos uma docente que parecia se esforçar para ajudar os alunos a ampliar suas habilidades argumentativas. Como foi dito, dentre as cinco professoras observadas, Maria foi a docente que mais realizou atividades em direção a essa finalidade. Perguntamos, então: quais seriam as concepções dessa professora e as dificuldades vividas por ela?

Por meio das observações de suas aulas foi possível perceber que a docente propiciava variadas propostas de leitura e escrita, envolvendo a circulação de diferentes gêneros. Desse modo, era uma professora que buscava favorecer o uso de diferentes habilidades importantes para a participação dos alunos em práticas sociais diversificadas,ainda que não tenha utilizado, nas aulas observadas, textos da ordem do argumentar. 
Blumenau, v. 11, n.1, p.138-158, jan./abr. 2016

DOI: http://dx.doi.org/10.7867/1809-0354.2016v11n1p138-158

Como vimos, a preocupação em ajudar os estudantes a lidar com situações em que as habilidades argumentativas são necessárias aparecia por meio de atividades de discussão e interpretação de textos cujos temas eram passíveis de debate. Nessa direção, vimos que ela desenvolveu três aulas dentro de um mesmo esquema didático: levantamento de uma questão ou leitura de um texto e discussão sobre o tema.

Por meio da entrevista, foi possível verificar que a professora tinha pouca clareza sobre quais gêneros poderiam ser escolhidos para ajudar a desenvolver habilidades argumentativas, pois afirmou, logo no inicio, que nunca tinha trabalhado com textos argumentativos, no entanto, ao serem listados alguns gêneros, ela declarou que já tinha contemplado, sim.

Nos momentos da entrevista em que pedimos que ela falasse sobre as capacidades argumentativas das crianças, a docente afirmou que elas eram capazes de argumentar, mas que dificuldades gerais de escrita impossibilitavam um trabalho mais efetivo de produção de textos argumentativos.

Em relação à leitura, foi observado, também, que as questões que a professora formulava com base no texto não enfocavam reflexões sobre os recursos linguísticos e estratégias discursivas dos autores. Com base em tais evidências, levantamos a hipótese de que,possivelmente,é a falta de reflexão consciente e sistemática sobre as práticas de linguagem e sobre as características dos gêneros que levam as docentes a realizarem muitas vezes intervenções didáticas pouco diversificadas de leitura e de escrita, tal como parecia ocorrer com Maria.

$\mathrm{Na}$ tarefa em que ela foi solicitada a analisar uma aula conduzida por outra professora, Maria mostrou que percebia a importância de estabelecer finalidades didáticas para as atividades propostas aos alunos, bem como da seleção de recursos que possibilitem o desenvolvimento de atitudes críticas. No entanto, ao analisar a conversa conduzida pela professora após o filme, não mencionou a exploração das estratégias discursivas usadas pelos personagens ou com a reflexão sobre o gênero usado na situação didática: debate. Além disso, não apontou a falta de planejamento ou de estímulo à reflexão sobre a situação de debate. Na aula analisada, o tema do filme e as questões por ele suscitadas não foram tratadas como objetos de investigação, análise e confronto de opiniões. Em sua análise, Maria não percebeu essa lacuna, talvez porque a sua própria prática também fosse 
Blumenau, v. 11, n.1, p.138-158, jan./abr. 2016

DOI: http://dx.doi.org/10.7867/1809-0354.2016v11n1p138-158

carente desse elemento, conforme foi visto na primeira etapa da pesquisa.

Por outro lado, Maria percebia, na aula analisada, que um aspecto negativo era o estilo muito diretivo da professora, em que o protagonismo da situação estava sempre do lado dela e raramente do lado dos alunos.De fato, pudemos observar nas aulas de Maria, que ela tendia a buscar uma participação maior dos estudantes, abrindo mais espaços de discussão, embora em vários momentos perdesse oportunidades de estimular o desenvolvimento dos argumentos pelas crianças ou da contra-argumentação relativa aos pontos de vista contrários.

Parecia haver uma concepção de que colocando os estudantes para discutir, de modo participativo, o ensino da argumentação estaria garantido. Essa concepção pode estar relacionada à baixa capacidade de perceber outras possibilidades didáticas voltadas para esse ensino, além de discussões sobre determinados temas suscitados pela leitura de um texto.

Enfim, pudemos perceber que, tanto nas aulas observadas, quanto nas descritas por Maria durante sua entrevista, bem como na tarefa de análise de um relatório de aula de outra professora, a docente parecia ter uma forma de ensinar a argumentar: Ler um texto, fazer perguntas e discutir. Na discussão observada em suas aulas também se ressalta uma mediação pouco consistente nos momentos de polêmica, em que opiniões contrárias são colocadas. Maria não parecia ter um modelo didático dos gêneros com os quais trabalhava e nem clareza sobre o que gostaria que seus alunos aprendessem.

Embora concebamos, assim como Lahire (1998), que nem sempre somos capazes de explicitar o que sabemos e o que fazemos, sem dúvidas, a reflexão consciente dos saberes pode dar maior poder de decisão, como defendem autores com Dolz e Schneuwly (2004). O professor pode, sem dúvidas, desenvolver ações didáticas pertinentes e relevantes e não saber falar sobre elas, mas, no caso de Maria, o que se observou não foi apenas um discurso precário sobre suas opções didáticas, e sim uma prática padronizada, pouco diversificada, e uma mediação que favorecia precariamente a aprendizagem dos estudantes, apesar do esforço da docente de contemplar princípios didáticos recorrentes no discurso atual sobre o ensino de língua materna.

A professora declarava a intenção de desenvolver alunos críticos. Mas suas estratégias pouco ajudavam a promover um ensino nesse sentido. 
Diante das análises conduzidas aqui é patente a importância de que as ações de formação inicial e continuada de professores incluam o estudo mais aprofundado de gêneros do discurso, incluindo-se os da ordem do argumentar. Ações em que os professores possam analisar as práticas de linguagem em que tais gêneros circulam, assim como as características desses gêneros, como suas finalidades mais recorrentes, as formas composicionais e as características linguísticas mais comumente encontradas. Simultaneamente, os programas de formação devem incluir ações em que os docentes possam socializar e planejar estratégias didáticas que favoreçam a produção e a compreensão de textos orais e escritos em situações de interação diversificadas. Tais temas são urgentes, dado que tais pressupostos são ainda novos no campo da educação e com poucas referências para auxiliar o professor nessa tarefa.

TELMA FERRAZ LEAL

Doutora em Psicologia Cognitiva; professora da Universidade Federal de Pernambuco: Departamento de Métodos e Técnicas de Ensino e Pós-Graduação em Educação.

\section{ANA CAROLINA PERRUSI BRANDÃO}

Doutora em Psicologia Cognitiva; professora da Universidade Federal de Pernambuco: Departamento de Métodos e Técnicas de Ensino e Pós-Graduação em Educação.

\section{SEVERINA ERIKA MORAIS SILVA GUERRA}

Mestre em Educação; Professora da Rede Municipal de Ensino de Recife.

\section{EDLA FERRAZ CORREIA CARVALHO}

Mestre em Educação; coordenadora pedagógica da Escola Conviver.

\section{REFERÊNCIAS}

ALMEIDA, E.G. A escrita argumentativa: avaliação de um programa de ensino com alunos das $2^{a}$ e $4^{a}$ séries. 2003. 178 f. Dissertação - Curso de Mestrado em Psicologia, Centro de Filosofia e Ciências Humanas, Universidade Federal de Pernambuco, Recife.

BAKHTIN, M. Estética da criação verbal. $3^{\text {a }}$ ed. ( $1^{\text {a }}$ ed. 1992). São Paulo: Martins Fontes, 2000. $421 \mathrm{p}$.

BEZERRA, M. A.. Textos: seleção variada e atual. In:DIONÍSIO, A.P. \&BEZERRA, M.A. O livro didático de Português: múltiplos olhares. Rio de Janeiro: Lucerna, 2001. P. 33-45. 
Blumenau, v. 11, n.1, p.138-158, jan./abr. 2016

DOI: http://dx.doi.org/10.7867/1809-0354.2016v11n1p138-158

BRASSART, D. G. Explicatif, argumentatif, desriptif, narratif et quelques autres, notes de travail, Recherches, n. 13, p.21-59, 1990.

CITELLI, A.Linguagem e persuasão. 15ª ed. São Paulo: Ática, 2000.77 p.

DOLZ, J. Learning argumentative capacities. A study of the effects of a systematic and intensive teaching of argumentative discourse in $11 / 12$ years old children. Argumentation, 10, n. 2, p. 227 - 251, 1996.

DOLZ, J.; SCHNEUWLY, B.Gêneros orais e escritos na escola. Campinas: Mercado das Letras. 2004. 278 p.

LAHIRE, B. Logiques pratiques: le "faire" et le "dire sur le faire". Recherche et Formation, Les savoirs de la pratique: un enjeu pour la recherche et la formation. INRP, n. 27, p. 15-28, 1998.

LEAL, T. F., BRANDAO, A. C. P., FRANCA, A. C., SILVEIRA, R. C.Concepções e práticas de professoras no ensino da argumentação no 50 ano do Ensino Fundamental. Práxis Educativa (Impresso), v.7, p.253 - 278, 2012.

LEAL, T. F., BRANDAO, A.C.P., TORRES, M. R. P.Leitura nos livros didáticos: a identificação de pontos de vista em textos escritos como objeto de ensino. Revista Educação em Questão, v.1, p.220 - 243, 2009.

LEAL, T.F. et al. Para escrever é preciso pensar! As orientações dos livros didáticos para escrita de textos da ordem do argumentar no Brasil. Revista Portuguesa de Educação, v. 23, p. 157-181, 2010.

LEAL, T.F.; MORAIS, A.G. A argumentação em textos escritos: a criança e a escola. Belo Horizonte: Autêntica, 2006. 243 p.

LOPES, S.F. Dissertar: uma perspectiva possível na alfabetização.1998. 37f. Monografia de Finalização de Curso de Especialização.Universidade Federal de Pernambuco, Recife.

MACHADO, I. Gêneros discursivos. In BRAIT, B.Bakhtin: conceitos-chave. São Paulo: Contexto, 2007, p. 151-167.

MACHADO, A. R.; CRISTÓVÃO, V. L. L. A construção de modelos didáticos de gêneros: aportes e questionamentos para o ensino de gêneros. In ABREU-

TARDELLI, L.S.; CRISTÓVÃO, V.L.L. (Org.). Linguagem e educação: o ensino e a aprendizagem de gêneros textuais. Campinas: Mercado de Letras, 2009, p. 123-151. PERELMAN, C.; OLBRECHSTS - TYTECA, L. Tratado da argumentação: a nova retórica. Trad. Maria Emantina Galvão. São Paulo: Martins Fontes, 1958/1999. 253p.

ROSENBLAT, E. Critérios para a construção de uma sequência didática no ensino dos discursos argumentativos. In: ROJO, R (org). A prática de linguagem em sala de aula: Praticando os PCNs. São Paulo: EDUC; Mercado das letras, 2000.p. 185-205. 
Blumenau, v. 11, n.1, p.138-158, jan./abr. 2016

DOI: http://dx.doil.org/10.7867/1809-0354.2016v11n1 p138-158

THIVES, P.F. As vozes sociais na constituição da identidade docente. Anais da ANPED Sul, Itajaí SC, 2008. 